\title{
RadiofRequency Stimulation OF InTERVERTEBRAL Discs
}

\author{
Steven Rosen, MD, and Frank Falco, MD
}

The etiology of discogenic pain is poorly understood. The most accepted theory has been that nociceptors in the outer one-third of the annulus fibrosis are responsible for transmitting pain secondary to internal disc disruptions. The concept of "neoneuralization" after disc injury has been disseminated. It has been noted that disc degeneration and injury are associated with

The mechanism of pain from internal disc disruption is poorly understood. Previous studies have shown sensory nerve endings confined to the outer one-third of the annulus fibrosis. The theory of "neoneuralization" has been suggested to describe the etiology of internal disc disruptions. Abnormal nerve ingrowth and expression of painful nociceptors have been thought to be the primary factor in painful internal disc disruptions. Numerous studies have implicated the outer annulus as a source of axial back pain $(1,2)$. Recently thermal lesioning has been advocated as a means of decreasing pain secondary to internal disc disruptions (3). Thermal lesioning has been advocated first using the Spinecath manufactured by Oratech and now also using the discTRODE manufactured by Radionics $(4,5)$. Published studies have been performed using the Spinecath and have shown a positive effect from thermal lesioning. However, the mechanism of thermal disc lesioning is unclear. It has been assumed that deafferentation of the outer annulus has been an important goal. Another proposed mechanism has been collagen modification. If deafferentation of the outer annulus was the primary mech-

From Fox Chase Pain Management Associates, Jenkintown, PA and Mid-Atlantic Spine, Newark, DE. Address Correspondence: Steven Rosen, MD, Fox Chase Pain Management Associates, The Pavilion, 261 Old York Road, Suite 707, Jenkintown, PA 19046 Email: foxchasepain@aol.com

Funding: There was no external funding in preparation of this manuscript. ingrowth of neural fibers into the disc annulus. One mechanism of Intradiscal Electrodothermal Therapy (IDET) has been thought to be lesioning of these nociceptors. Five consecutive patients were studied using an intraannular electrode. The Radionics ${ }_{T M}$ discTRODE $^{T M}$ was used. It was found impossible to selectively stimulate axial pain fibers using this system. Radicular stimu-

lation was noted in all patients at all levels studied. The implication of these findings concerning the concept of neoneuralization, mechanism of IDET, and possible strategies to decrease discogenic pain are discussed.

Keywords: Stimulation, Intervertebral Disc, IDET, Discogenic Pain

anism, one would assume that pain relief would occur in the short-term as soon as the temperature of the outer annulus was over 42 degrees. However this does not correlate with the clinical finding that patients can have severely increased pain after the procedure lasting up to six weeks. The fact that patients slowly improve with time implies that collagen modification and remodeling may be the primary mechanism in successful Intradiscal Electrodothermal Therapy (IDET). Thermal lesioning with the IDET Spinecath was first described by the Saal brothers (6). Most studies have

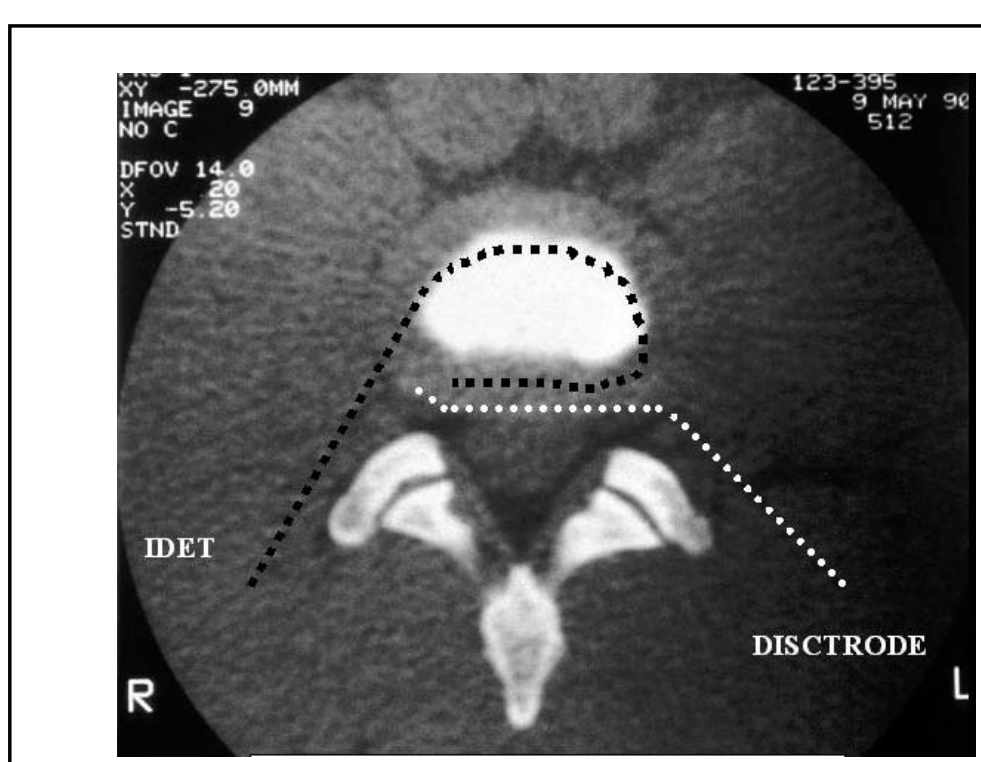

Fig 1. Placement of Spinecath and discTRODE

shown success rates between 50 and $70 \%$ in decreasing discogenic pain.

This study was performed with the discTRODE ${ }^{\mathrm{TM}}$ manufactured by Radionics. The discTRODE is an electrode placed in the outer annulus (Fig.1). The presumed advantage over the Spinecath is placement of the heat source closer to or into the outer annulus. Recent studies by Kleinstueck have shown that the temperatures required to ablate nerves or induce collagen shrinkage were not observed except in a very limited margin surrounding the Spinecath $(7,8)$. During the discTRODE procedure 


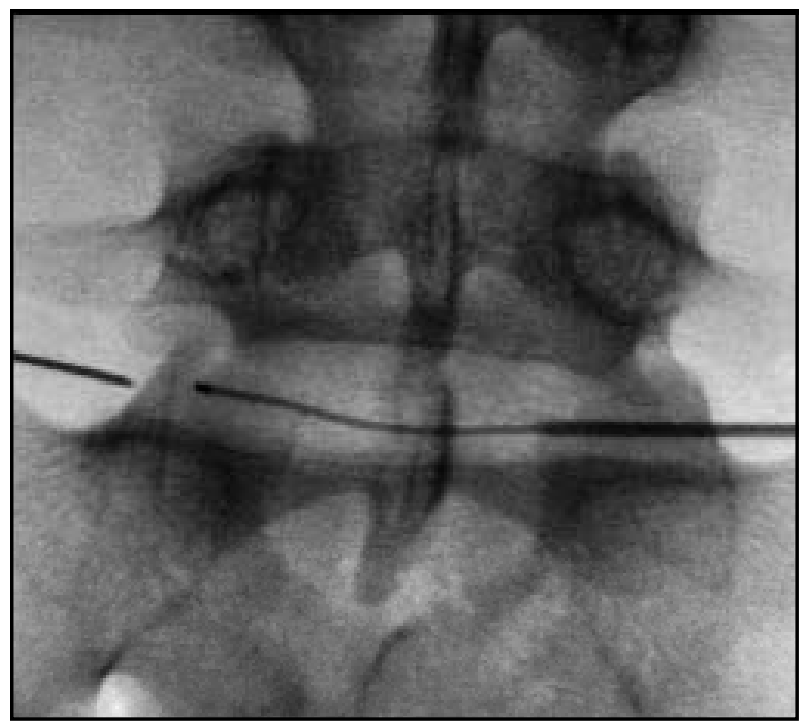

Fig 2. Anterior and Posterior Views of Introducer, discTRODE and SMK Electrode

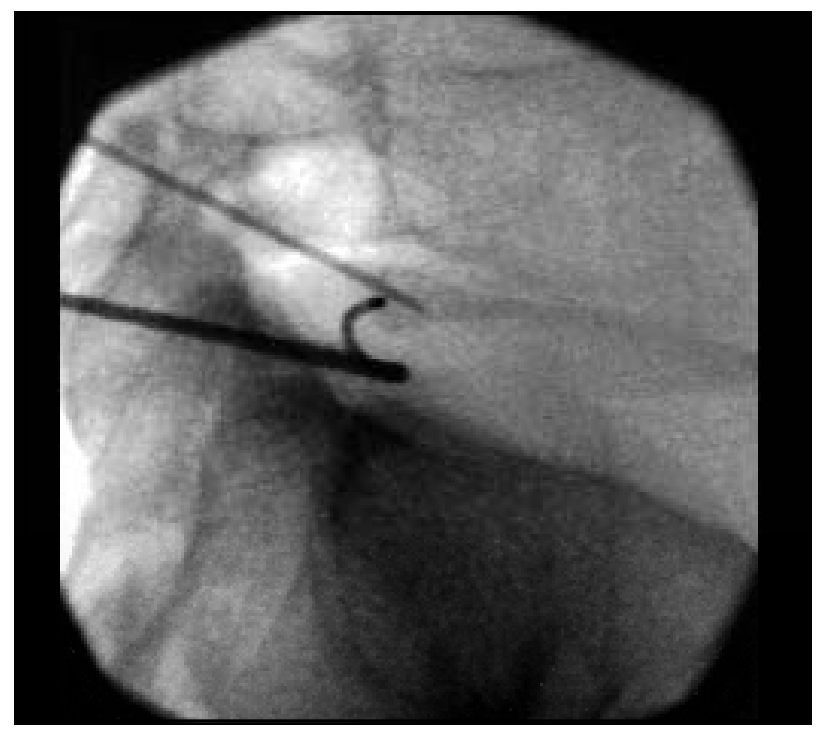

Fig 3. Lateral View of Introducer, discTRODE and SMK Electrode a conducting wire is passed thru the outer annulus using an extrapedicular approach. A contralateral thermocouple is placed through another extrapedicular approach to monitor temperature changes during the procedure. Outer annular temperatures during the procedure are measured using the contralateral thermocouple. The discTRODE is heated to at least 60 degrees to ensure collagen remodeling and that the outer annulus is at least 42 degrees to ensure denervation of annular nociceptors.

The theory that intervertebral disc stimulation is secondary to pressurization and sensitization of the outer annular nociceptors has been largely accepted during the last decade. The dorsal ganglion has been largely overlooked as a pain producing structure. A recent study showed that disc stimulation during thermal lesioning with the Spinecath reproduces the patient's pain as noted during discography and is concordant with patient's usual pain syndrome (9). However, it is noted that most complications from thermal lesioning are neuropathic in origin. While there have been reports of vertebral body osteonecrosis and accelerated disc degeneration (10), the majority of complications are neuropathic in origin. These have included cauda equina syndromes (11). A recent article describing complications of Intradiscal Electrothermal Therapy describes the most common complications as new paresthesias in a non-dermatomal distribution (12). These complications have been generally self-limit- ed. The original goal of this study was to electrically stimulate the outer annulus. It was felt that if electrical stimulation of the outer annulus was possible then neuromodulatory techniques could decrease pain in patients with internal disc disruptions recalcitrant to standard therapies.

\section{Methods}

Patients were chosen in a standard manner. The age of the patients ranged from 23 to 56. The sex distribution was 2 male and 3 female. All patients had internal disc disruption with pain reproduced by discography. All discTRODE

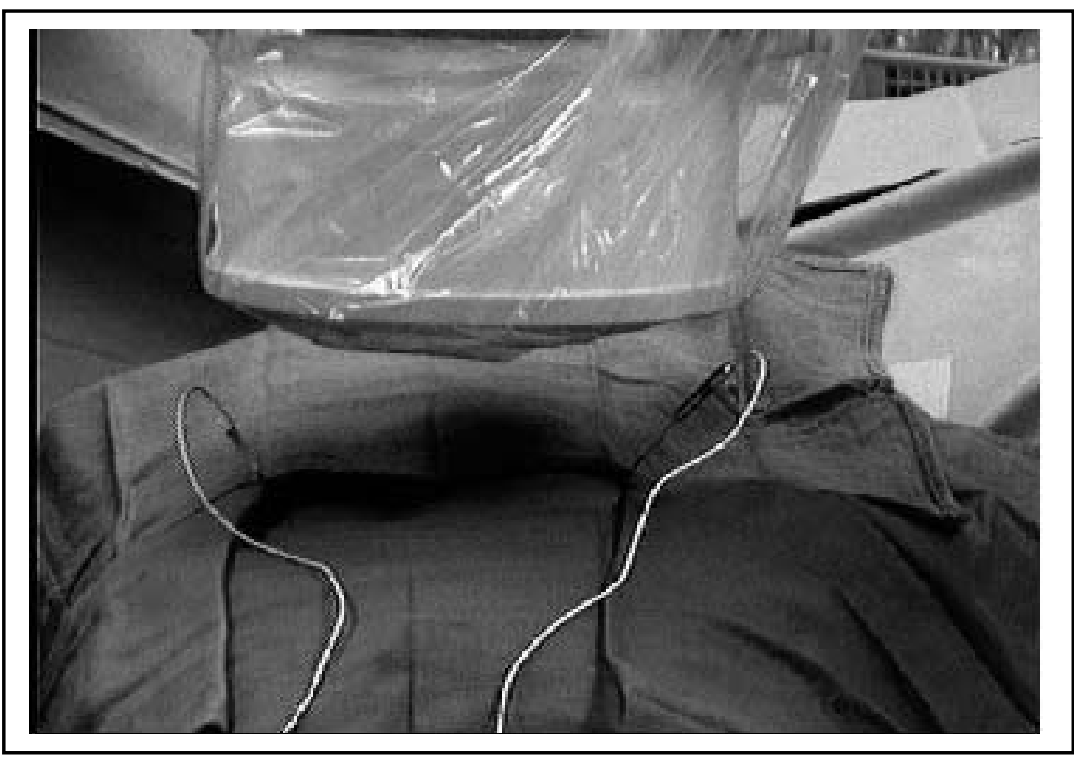

Fig 4. discTRODE and SMK Electrode procedures were performed in either one or two adjacent discs. All patients had a negative control level and all levels showed low-pressure concordant provocation of the disc annulus. A subsequent CT scan showed radial tears. A Radionics RFG-3C+ lesion generator was used. A 17 gauge insulated introducer needle was used. A contralateral approach to the most painful side was used. The discTRODE was placed through the outer annulus to the painful side without difficulty in all cases (Fig.2 and Fig.3). The annulus was identified using a combination of impedance and fluoroscopic 
monitoring. The measured impedance would decrease dramatically as the annulus was entered. The impedance of the discTRODE was $100 \mathrm{ohms}$. Stimulation was performed at 2 hertz and 50 hertz to predominantly stimulate first motor and then sensory fibers. If only contralateral stimulation to the side of insertion was noted the introducer needle was pulled back until bilateral stimulation was noted. A contralateral thermocouple was used at all levels and inserted just into the outer annular fibers as determined by impedance monitoring and fluoroscopy (Fig.4). All patients were sedated during introduction of the introducer needle, discTRODE, and contralateral thermocouple but were alert and awake during disc stimulation and heating. Thermal lesioning was begun at 50 degrees and then increased by a maximum of 5 degrees every three minutes until the discTRODE temperature was at least 60 degrees to ensure collagen modification. Temperature was then increased until the outer annular temperature was noted to be at least 42 degrees. If painful paresthesias were noted the temperature was decreased until they disappeared.

\section{RESULTS}

Results are summarized in Table 1. Five patients were studied. However subsequent patients were noted to have sim- ilar and entirely reproducible findings. Stimulation thresholds were between 0.8 and 1.5 volts. There was no difference between motor and sensory stimulation thresholds. The patients all described a burning uncomfortable sensation in their legs. Two patients described axial back stimulation but only after stimulation of the lower extremities was noted and only at voltages that were extremely painful. If stimulation was only on the side contralateral to the insertion of the discTRODE, the introducer needle was then pulled back until bilateral stimulation was noted. Six discs were studied. One patient had both L4-5 and L5-S1 studied. All findings were reproduced at least twice before thermal lesioning was performed. No discs were noted to produce comfortable stimulation. All stimulation was nondermatomal. Results were tabulated after six weeks. Four lesions were performed at L5-S1, one at L4-5, and one at L3-4. One patient noted no change in pain at threemonth follow up. Four patients noted decreased leg pain after six weeks. Two patients noted decreased back and leg pain after six weeks. At all levels radicular stimulation was primarily obtained. All patients are still being followed for chronic pain control. So far 4 out of the 5 patients obtained at least 6 months of partial benefit and one patient had no benefit. No intraoperative complications were noted.

\section{DISCUSSION}

All patients noted stimulation in the lower extremities. There was no difference between motor and sensory thresholds. Surprisingly only two patients noted back stimulation and these were at high voltages and were painful. Stimulation was always radicular rather than axial. While possible that these stimulation patterns were specific to the Radionics discTRODE, this is unlikely.

The results imply that while neoneuralization may be noted on histological specimens it may not be the etiology of low back pain. The results noted are more consistent with stimulation of the dorsal ganglion. Ipsilateral stimulation of the contralateral dorsal ganglion was noted and then bilateral ganglion stimulation was noted after the introducer was pulled back. This correlates with recent studies showing that while not common, neuropathic and radicular complications occur after thermal lesioning. These results are also similar to patients who have had radiofrequency partial percutaneous ganglionotomies. Typically the patients can have a substantial neuritis lasting up to six weeks before the pain decreases. They can note benefit lasting up to one year. This also correlates with the fact that denervation of outer annular nerve fibers would be expected to give more immediate relief. The implication is that long-

Table 1. Disc Stimuulation

\begin{tabular}{|c|c|c|c|c|c|c|}
\hline $\begin{array}{l}\text { Patient } \\
\text { DOS }\end{array}$ & Level & $\begin{array}{l}\text { Sensory } \\
\text { Threshold }\end{array}$ & $\begin{array}{c}\text { Motor } \\
\text { Threshold }\end{array}$ & Quality & $\begin{array}{c}\text { Max } \\
\text { Temperature Time }\end{array}$ & Result \\
\hline $\begin{array}{c}\text { L.D. } \\
\text { 12/05/02 }\end{array}$ & L3-4 & $\begin{array}{l}0.85 \text { Volts } \\
\text { back, buttocks, bilateral } \\
\text { lower extremities }\end{array}$ & Same & Burning & $\begin{array}{c}67 \text { degrees for } \\
2 \text { minutes then } 65 \\
\text { degrees for } 6 \text { minutes }\end{array}$ & $\begin{array}{l}\text { Decreased } \\
\text { back and } \\
\text { leg pain at } \\
2 \text { months }\end{array}$ \\
\hline $\begin{array}{c}\text { C.B. } \\
12 / 17 / 02\end{array}$ & $\begin{array}{l}\mathrm{L} 4-5 \\
\mathrm{~L} 5-\mathrm{S}_{1}\end{array}$ & $\begin{array}{l}\text { 0.8 Volts } \\
\text { lower extremity }>\text { back } \\
1.2 \text { Volts } \\
\text { lower extremity }> \\
\text { back }\end{array}$ & $\begin{array}{l}\text { Same } \\
\text { Same }\end{array}$ & $\begin{array}{l}\text { Uncomfortable } \\
\text { Uncomfortable }\end{array}$ & $\begin{array}{l}62 \text { degrees for } \\
3 \text { minutes } \\
65 \text { degrees for } \\
3 \text { minutes }\end{array}$ & $\begin{array}{l}\text { No change } \\
\text { in pain } \\
\text { at three } \\
\text { months }\end{array}$ \\
\hline $\begin{array}{c}\text { D.B. } \\
12 / 19 / 02\end{array}$ & $\mathrm{~L}_{5}-\mathrm{S}_{1}$ & $\begin{array}{l}\text { o.85 Volts } \\
\text { buttocks, then } \\
\text { ipsilateral } \\
1.1 \text { Volts bilateral } \\
\text { buttocks and lower } \\
\text { extremities }\end{array}$ & Same & Painful & $\begin{array}{c}65 \text { degrees for } \\
4 \text { minutes }\end{array}$ & $\begin{array}{l}\text { Decreased } \\
\text { leg pain at } \\
6 \text { weeks }\end{array}$ \\
\hline $\begin{array}{c}\text { A.F. } \\
01 / 02 / 03\end{array}$ & L5-S1 & $\begin{array}{l}\text { 1.2 Volts } \\
\text { right lower extremity } \\
1.5 \text { Volts } \\
\text { left lower extremity }\end{array}$ & Same & Painful & $\begin{array}{l}68 \text { degrees for } \\
3 \text { minutes }\end{array}$ & $\begin{array}{l}\text { Decreased } \\
\text { back and } \\
\text { leg pain at } \\
10 \text { weeks }\end{array}$ \\
\hline $\begin{array}{c}\text { E.S. } \\
02 / 20 / 03\end{array}$ & L5-S1 & $\begin{array}{l}\text { 1.1Volts } \\
\text { bilateral lower } \\
\text { extremities }\end{array}$ & Same & Painful & $\begin{array}{l}60 \text { degrees for } \\
6 \text { minutes }\end{array}$ & $\begin{array}{l}\text { Decreased } \\
\text { leg pain at } \\
6 \text { weeks }\end{array}$ \\
\hline
\end{tabular}


term benefit from an IDET procedure may be either secondary to collagen remodeling, a partial percutaneous ganglionotomy, or to an unknown mechanism. Four of the five patients in this study obtained six months of partial relief.

These findings stimulate much cause for discussion. The original thought was that if stimulation of the axial back pain fibers was possible then stimulation with commercially available neuromodulatory leads would be appropriate to decrease pain in patients with recalcitrant internal disc disruptions. If the painful structure truly is the dorsal ganglion, attempts to neuromodulate the dorsal ganglion may be more successful in decreasing discogenic pain. The mechanism of discography may not be sensitization of nociceptors in outer annulus. It may be irritation of nociceptors in the dorsal ganglion after pressurization of the intervertebral disc.

\section{ConcLusion}

To summarize, disc stimulation using the Radionics discTRODE was performed on five consecutive patients. Radicular stimulation was noted in all patients with no change between motor and sensory thresholds. Axial back stimulation occurred only in two patients at high amplitudes. The theory of neoneuralization and sensitization of nociceptors in the outer annulus may not apply to pain from internal disc disruptions. The mechanism of IDET lesioning remains unknown. It may well be secondary to collagen modification of the outer annulus. It may be secondary to partial denervation of the dorsal ganglion. It may be from a mechanism still unknown. Hopefully this article will stimulate further investigations into the etiology of painful internal disc disruptions and allow us to find a technique to better treat this unfortunate and large subset of chronic pain patients.

\section{Author Affiliation:}

Steven Rosen, MD

Fox Chase Pain Management Associates

The Pavilion

261 Old York Road, Suite 707

Jenkintown, PA-19046

Email: foxchasepain@aol.com

Frank Falco, MD

Mid-Atlantic Spine

139 East Chestnut Hill Road

Newark, DE-19713

Email: ffalco@midatlanticspine.com

\section{RefERENCES}

1. Coppes MH, Marani E, Thomeer RT et al. Innervation of "painful" lumbar discs. Spine 1997;22:2342-2349.

2. Freemont AJ, Peacock TE, Goupille $P$ et al. Nerve ingrowth into disease intervertebral disc in chronic back pain. Lancet 1997;350:178-181

3. Wetzel FT, McNally T, Phillips F. Intradiscal electrothermal therapy used to manage chronic discogenic low back pain. Spine 2002;27:2621-2625.

4. Karasek M, Bogduk N. Twelve-month follow-up of a controlled trial of intradiscal thermal annuloplasty for back pain due to internal disc disruption. Spine 2000;25: 2601-2607.

5. Wright R. Radiofrequency annuloplasty for lumbar discogenic pain. In Sluijter M. Radiofrequency Part I. FlivoPress SA, Switzerland, 2001, pp149-69.

6. Saal JA, Saal JS. Intradiscal electrothermal treatment for chronic discogenic low back pain: A prospective outcome study with minimum 1-year follow-up. Spine 2000;25: 2622-2627.

7. Kleinstueck FS, Diederich CJ, Nau WH, et al. Acute biomechanical and histological effects of intradiscal electrothermal therapy on human lumbar discs. Spine 2001;26:2198-2207.

8. Kleinstueck F, Diederich C, William N, Puttlitz C, Smith J, Bradford D, Lotz J. Temperature and thermal dose distributions during intradiscal electrothermal therapy in the cadaveric lumbar spine. Spine 2003;28: 1700-1709.

9. O'Neill C, Kurgansky M, Derby R, Ryan D. Disc stimulation and patterns of referred pain. Spine 2002;27:2776-2781.

10. Scholl B, Theiss S, Lopez-Ben R, Kraft $M$. Vertebral osteonecrosis related to intradiscal electrothermal therapy. Spine 2003;28:E161-E164.

11. Ackerman W. Cauda equina syndrome after intradiscal electrothermal therapy. Reg Anesth Pain Med 2002;27:622.

12. Cohen S, Larkin T, Salahadin A, Chang A, Stojanovic M. Risk factors for failure and complications of intradiscal electrothermal therapy: A pilot study. Spine 2003;28:1142-1147. 